\title{
Adaptación iconográfica de los descriptores del índice de inclusión para Colombia
}

\section{Iconographic adaptation of descriptors of the index inclusion for Colombia}

\author{
Diana Vanessa Vanegas Montoya *, Eliana María Tabares Peláez**
}

\begin{abstract}
Resumen
El índice de inclusión de Colombia es una herramienta que se utiliza en las instituciones educativas para conocer la percepción que tiene la comunidad frente a la atención de la diversidad y fue diseñado en un único formato que limita la comprensión del código alfabético convencional de la lengua castellana. El análisis de esta situación lleva a proponer la investigación sobre la adaptación iconográfica de los descriptores del cuestionario correspondiente a dicho índice mediante la comparación de técnica de imágenes globales y pictográficas. Para ello se tomaron como muestra 16 estudiantes que utilizan diferentes códigos de comunicación y que presentan las siguientes características: discapacidad auditiva, cognitiva o autismo de alto funcionamiento y sin castellano escrito; y 8 padres de familia que no manejen el código alfabético convencional. Se llegó a la conclusión de que las imágenes globales favorecen mayores niveles de accesibilidad del instrumento.
\end{abstract}

Palabras clave: Accesibilidad; Iconografía; Gestión inclusiva; Lenguaje accesible.

Licenciada en Educación Preescolar, Docente Centro Educativo Niños del Futuro, diana_vanessa_v@hotmail.com

** Licenciada en Educación Preescolar, Docente Fundación Mónica Uribe por Amor, elianamariatabares@hotmail.com 
Abstract:

The inclusion rate in Colombia is a tool, that is used in educational institutions to determine the perception of the community against the attention to diversity, was designed in an only format that limits the understanding of conventional alphabetic code. The analysis of this situation leads to propose the adaptation research iconographic questionnaire descriptors corresponding to this rate by comparing global images technique and pictographics, taking as a sample on 16 students using different codes of communication and have the following features: hearing impairment, cognitive functioning autism and without the high castilian spanish written, and parents who do not drive conventional alphabetical code. Concluding that the global images favor higher levels of accessibility of the instrument.

Keywords: Accessibility; Iconographic; Inclusive management; Accessible language.

El índice de inclusión de Colombia, del Ministerio de Educación Nacional (2008), es una herramienta que se utiliza en las instituciones educativas para conocer la percepción que tiene la comunidad frente a la atención de la diversidad. Fue diseñado en un único formato que limita el acceso de la población estudiantil y padres de familia, por ejemplo, de quienes presentan analfabetismo o condiciones que restringen la comprensión del cuestionario: personas con discapacidad auditiva, cognitiva, autismo o que utilicen diferentes códigos de comunicación y que no se corresponde con el castellano escrito.

El análisis de esta situación lleva a proponer la investigación sobre la adaptación iconográfica de los descriptores del cuestionario correspondiente al índice de inclusión con el fin de contribuir al logro de mayores niveles de accesibilidad del instrumento a las poblaciones antes mencionadas y a la comunidad educativa en general. Además, se propone diseñar unas fichas que contienen imágenes en las que se plasma el contenido de cada uno. Se permite la participación en la evaluación de la atención de la diversidad y posibilita la valoración de cómo es vivida la inclusión en las instituciones educativas del país.
El proceso de adaptación surge de la idea basada en el concepto de iconografía. Para Sebastián "desde el punto de vista etimológico, la palabra iconografía consta de dos vocablos de origen griego: eikon (imagen) y graphein (descripción), es, por tanto, la ciencia que trata de la descripción de las imágenes" (1994, pp .47-69), y usada por primera vez por Furetiere, en 1701. El concepto de iconografía ha tenido una representación relevante en el arte y en este proyecto se traslada a las ciencias humanas. Aquí se parte de que el ser humano inicia su proceso lector desde que tiene el primer contacto con el mundo exterior, el aprendizaje de signos y códigos es fundamentalmente cultural. Un niño, en la etapa inicial de su desarrollo, hace lectura de símbolos, colores, formas, imágenes. Esta información se la suministra el medio en el que se desenvuelve y la lectura es la caracterización de los símbolos escritos y su reconocimiento en un contexto determinado. De allí que se pueda concluir que los idiomas son aprendidos desde la cultura.

Tomando el concepto de pictograma, Royo, Neupomuceno, Salguero y Quesada: 
Es un diagrama que utiliza imágenes o símbolos para mostrar datos para una rápida comprensión, también llamada gráfica de imágenes o pictografía. En un pictograma se utiliza una imagen o un símbolo para representar una cantidad específica de palabras. Los pictogramas son gráficos con dibujos alusivos al carácter que se está estudiando y cuyo tamaño es proporcional a la frecuencia que representan; dicha frecuencia se suele representar (pp.179 - 44).

La iconografía, tiene en cuenta el concepto de accesibilidad. Para el Ministerio de Educación Nacional (2006):

"Alude al derecho ciudadano por el cual toda persona, sin importar su edad y sus condiciones personales y sociales, puede disfrutar plenamente de todos los servicios que presta y ofrece la comunidad, como la comunicación, los espacios urbanísticos, arquitectónicos, vivienda, servicios públicos, medios de transporte, de tal forma que todas las personas puedan llegar, acceder, usar, y salir de forma autónoma, segura y confortable (p. 24).

Es preciso anotar que un instrumento es accesible cuando permite la participación de todas las personas en la valoración de la gestión inclusiva de las instituciones educativas del país. El Ministerio de Educación Nacional entiende por gestión inclusiva "todas las actividades de promoción, planeación, implementación, seguimiento y evaluación que realizan las instituciones desde la gestión, para atender con calidad y equidad las necesidades en el aprendizaje, la participación y la convivencia de su comunidad educativa" (2008, p. 24)."

Una variable para tener en cuenta corresponde al lenguaje, puesto que en la actualidad existen diversas formas de comunicación que se adaptan a las características de las personas; en este sentido Henry expresa que "la accesibilidad no sólo implica la necesidad de facilitar acceso, sino también la de facilitar el uso" (2002).

Para la adaptación del índice, se tiene en cuenta la idea de Henry: "un diseño será accesible cuando sea usable para más personas en más situaciones o contextos de uso, posibilitando a todos los usuarios, de forma eficiente y satisfactoria, la realización y consecución de tareas. Para complementar el argumento, Nielsen (2001), propone que la "accesibilidad debe ser entendida como 'parte de', y al mismo tiempo 'requisito para', la usabilidad".

Se puede concluir que la accesibilidad de la información supone que cualquier persona debe poder y disponer de ella, tener las mismas oportunidades, beneficios y disfrutar de las mismas ventajas que las otras. Se entiende la accesibilidad en relación con las dos formas básicas, comunicación y comprensión; la accesibilidad en el lenguaje debe transmitir la información a los niños, niñas y padres de familia que observen los descriptores del índice de inclusión, es decir, la comunicación se hace a través del canal de las imágenes adaptadas en pictogramas.

\section{METODOLOGÍA}

La propuesta se enmarca en un tipo de investigación exploratoria con un diseño metodológico de comparación de dos aplicaciones. Para García Ferrer "El objetivo principal de los diseños exploratorios es proporcionar ideas que no han surgido en la búsqueda de fuentes secundarias, o ideas que si bien surgieron en esta pesquisa no están totalmente perfiladas” (2005, p. 42). 
La exploración se realiza a partir de validar la pertinencia de los descriptores adaptados con el uso de imágenes globales y de segmentación iconográfica, ambas universalmente reconocidas, que se plasman para representar el contenido de cada descriptor que hace parte del cuestionario. Esta metodología permite accesibilidad en el lenguaje, específicamente en las personas que no saben leer ni escribir o que tienen limitación en su comprensión.

\section{La investigación se orienta por los siguientes objetivos:}

El objetivo general:

- Validar un instrumento piloto sobre el cuestionario del índice de inclusión contextualizado a Colombia para comparar imágenes globales y de segmentación iconográfica, que posibiliten a estudiantes y familias sin código alfabético convencional, la comprensión de los descriptores propuestos para la autoevaluación de la gestión inclusiva en las instituciones educativas del país.

Objetivos específicos:

- Adaptar en imágenes iconográficas o globales los descriptores del índice de inclusión para Colombia que permita a estudiantes y familias la comprensión y autoevaluación sobre el enfoque de inclusión en la gestión de las instituciones educativas.

- Analizar la pertinencia del cuestionario adaptado en imágenes iconográficas o globales de los descriptores del índice de inclusión a partir de la aplicación a estudiantes y familias en algunas instituciones educativas del país.

- Diseñar un instrumento sobre imágenes accesibles que permitan la comprensión de los descriptores del índice de inclusión.

El proceso para el diseño del instrumento adaptado en imágenes, es el siguiente:

- Selección de imágenes universalmente reconocidas, que representen acciones correspondientes a los descriptores del cuestionario del índice de inclusión, que favorezcan la interpretación $y$ el uso del lenguaje en estudiantes y familias. Las imágenes se seleccionan en internet y buscan un diseño en forma de pictograma. Estas imágenes se extraen de Google.

- Adaptación de los descriptores del cuestionario con las imágenes seleccionadas, globales o en pictogramas; se eligen las que más se acomoden al contenido de cada uno y se relacionan las imágenes con los contenidos del descriptor, en el caso de las globales, o con palabras, en los pictogramas.

- Elaboración de una guía cualitativa de validación para ser utilizada con la muestra seleccionada y se evalúa la accesibilidad del lenguaje, tanto en imágenes globales como en pictogramas.

- Se aplica el cuestionario adaptado a una muestra de niños y familias sin código alfabético convencional, en dos momentos. El primero, en imágenes en pictogramas y, el segundo, en imagen global. 
Se toma una muestra de 16 estudiantes que utilizan diferentes códigos de comunicación y que presentan las siguientes características: discapacidad auditiva, cognitiva, autismo de alto funcionamiento $\mathrm{y}$ sin el castellano escrito; y ocho (8) padres de familia que no manejen el código alfabético convencional. Se aplica de forma individual una guía de preguntas cualitativas para evaluar la condición de interpretación y coherencia con la respuesta. Se hace a través de de una entrevista que permita llegar a la reflexión sobre la imagen en forma de pictograma o global. El entrevistador observa y analiza cómo se desarrolla la correspondencia entre la imagen y la interpretación que realizan los estudiantes y familias al descriptor del índice de inclusión y se corrobora con la respuesta brindada en el cuestionario.

- Análisis de la pertinencia en la aplicabilidad de las imágenes globales o en pictogramas que brindan información de la situación que evalúe el descriptor del índice.

- Selección de las imágenes que posibiliten la comprensión de los descriptores del índice de inclusión para diseñar el cuestionario adaptado.

\section{RESULTADOS}

Cuando se aplicó el cuestionario adaptado en forma de pictograma (imagen segmentada) a estudiantes y padres de familia sin código alfabético convencional, se observó y registró en la guía de preguntas que el lenguaje no fue accesible. Este hallazgo se justifica en el hecho de que la imagen estaba acompañada por una serie de conectores que la población no reconocía y se confundía a la hora de verbalizar el concepto para interpretarlo. La presencia de varias imágenes para un descriptor no posibilita su comprensión; el mensaje compuesto a través de varias imágenes, unidas por conectores en forma de imágenes, complejiza la lectura del descriptor del índice de inclusión.

Cuando se interactúa con el cuestionario adaptado en una imagen global, es decir, que represente el mensaje total del descriptor, facilita la comprensión y logra la interpretación de su contenido y posibilita la verbalización de respuestas coherentes y significativas. Allí se resalta la accesibilidad en el lenguaje e incremento de la participación en la aplicación del cuestionario.

Se concluye que la imagen global permite mayor accesibilidad en la comprensión de los descriptores del índice de inclusión y se toma la decisión de adaptar el cuestionario con este diseño.

\section{DISCUSIÓN DE RESULTADOS}

La propuesta de investigación aborda como eje principal la adaptación iconográfica, relevante en el desarrollo cognoscitivo y comprensión del lenguaje; la imagen global se ha utilizado como estrategia en otras investigaciones realizadas con poblaciones que no manejan código alfabético convencional, se correlaciona la experiencia de Villa (2008) de la Universidad de Antioquia, en una propuesta de alfabetización visual para estudiantes de básica, apoyada en recursos Hipermediales: "describe los aspectos técnicos que se tuvieron en cuenta en la elaboración de un entorno hipermedial diseñado específicamente con el propósito de favorecer la lectura de imágenes en estudiantes de educación básica”, hace un 
Tdea Diana Vanessa Vanegas Montoya, Eliana María Peláez.

aporte a la comprensión de la lectura de las imágenes en contenidos que tengan textos, videos, imágenes y audio en un conjunto que interactúe con los usuarios.

La investigación de Permalete (2006) plantea que "las personas con discapacidad se encuentran capacitadas y puedan tener acceso al desarrollo tecnológico y ocupar el lugar que les corresponde en la toma de decisiones que afectan su vida”. Los resultados en la aplicación de la validación del cuestionario del índice de inclusión da cuenta de que la accesibilidad del lenguaje, en relación con las formas básicas de comunicación y comprensión, posibilita lo expresado por Henry (2002) en acceso y uso.

\section{CONCLUSIONES}

- La adaptación de los descriptores del índice de inclusión, desde criterios de accesibilidad en el lenguaje con imágenes globales, permite a toda la población que presenta algún tipo de discapacidad, enfrentarse al instrumento y dar respuestas a la gestión inclusiva en las instituciones educativas del país.

- Iniciar procesos orientados a la promoción de adaptaciones en imágenes globales, implica asumir un pensamiento de reflexión hacia la inclusión para que toda la población diversa pueda participar de manera activa y equitativa.
- Los cuestionarios con las adaptaciones se pueden utilizar como materiales de apoyo en múltiples intervenciones didácticas, que incentivan la toma de decisiones, potencian su motivación en la combinación de lenguajes que favorecen el desarrollo de competencias específicas. Además, contribuyen a que los beneficiarios se familiaricen con las estructuras narrativas en imágenes propias de estos materiales.

- En los primeros años del niño y la niña es importante enriquecer ambientes con sonidos, imágenes globales, gusto, olor, de manera que la información llegue a los nervios sensoriales para que envíen mensajes al sistema nervioso central, especialmente al cerebro, donde los mensajes adquieren significado y comienza la percepción y la comprensión en forma global.

\section{Anexo. PROPUESTA DE INDICADORES ADAPTADOS EN IMAGEN GLOBAL}

A continuación se referencia un ejemplo de la adaptación del cuestionario del índice de inclusión para Colombia.

Descriptor A.1.1: La institución educativa admite a toda la población del sector sin discriminación de raza, cultura, género, ideología, credo, preferencia sexual, condición socioeconómica o situación de vulnerabilidad, como: desplazamiento, violencia y analfabetismo, entre otros. 


\section{Referencias}

Ángel Nepomuceno, Francisco J. Salguero, Francisco José Salguero Lamillar, José Francisco Quesada. (2001). Información, tratamiento y representación.

Camacho Ruiz, Sandra. (2007). La inclusión educativa, autoría temática: la inclusión en el sistema educativo. Centro, localidad, provincia, Granada. Recuperado de http://sepiensa.org.mx/ contenidos/2006/1_iconografia/icono1. htm

García Ferrer, Gemma. (2005). Investigación Comercial. 2. Ed. Madrid: Ediciones Esic Editorial. Madrid, España 2. Ed

González De Zárate, J.M. (1991). Método iconográfico. Vitoria. Ed. Ephialte (Institutos de estudios iconográficos). Recuperado de http://usuarios. multimania.es/odiseomalaga/Art_02.htm

Henry, ShawnLawton.(2002). Understanding Web Accessibility en Constructing Accessible Web Sites. Glasshaus.: April 2002. ISBN: 1904151000. Recuperado de http://www.macromedia.com/ macromedia/accessibility/pub/acc_sites_ chap01.pdf

Ministerio de Educación de Colombia (2008). Guía y Herramienta 34, Educación Inclusiva con calidad "Construyendo Capacidad Institucional para la Atención a la Diversidad". Recuperado de http:// www.slideshare.net/beruscka/inclusioneducativa
Ministerio de Educación Nacional. (2006). Fundamentación conceptual para la atención en el servicio educativo a estudiantes con NNE, Guía No.12., Bogotá.

Namakforoosh Mohammad, Naghi. (2005). Metodología de la Investigación. México: Limusa, 2 Edición, Capítulo 4.

Nielsen, Jacob. (2001). Beyond Accessibility, Treating People with Disabilities as People. Alertbox, 11 de Noviembre de 2001. Recuperado de http://www.useit. com/alertbox/20011111.html

Pernalete, Natividad. (2006, enero-junio). Tercer entorno y discapacidad. Revista Venezolana de Ciencias Sociales, (206224). Recuperado de http://redalyc. uaemex.mx/redalyc/src/inicio/ ArtPdfRed.jsp?iCve $=30910112>$ ISSN 1316-4090

Royo, Javier, (2004). Diseño Digital. Barcelona: Ediciones Paidós Ibérica.S.A. Recuperado de http://www.paidos.com

Santiago, Sebastián. (1994). Mensaje Simbólico, del Arte Medioeval. Madrid,

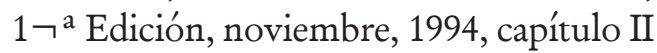
(47-69). 1ª Reimpresión marzo 1996.

Villa Orrego, Nora Helena. (2008, enerojunio). Propuesta de alfabetización visual para estudiantes de educación básica apoyada en recursos hipermediales: Un aporte a la comprensión lectora. Revista Interamericana de Bibliotecología. (207225). Recuperado de http://redalyc. uaemex.mx/src/inicio/ArtPdfRed. jsp?iCve $=179014347009>$ 


\section{Tes}

\section{Cibergrafía}

http://www.catedu.es/arasaac/

http://office.microsoft.com/es-hn/imágenes

http://pensandoenimaxes.blogspot.

com/2008_09_01_archive.html,teniendo. 